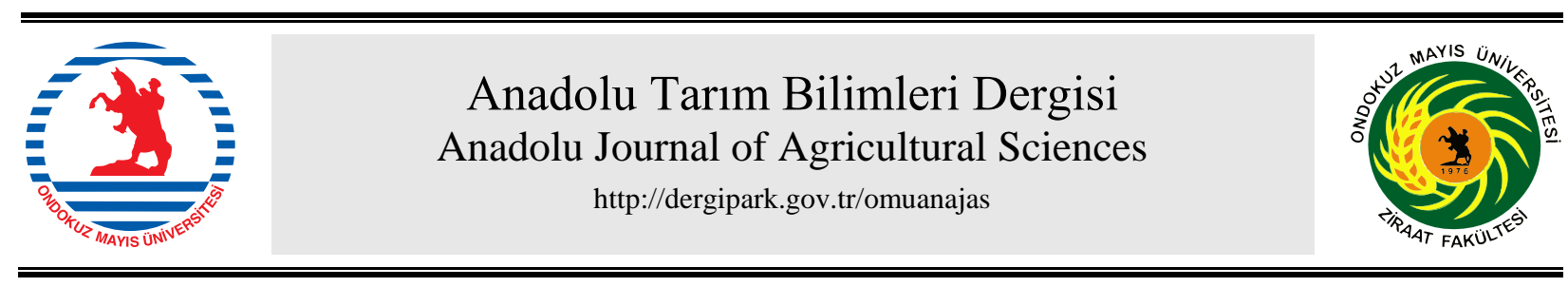

Araştırma/Research

\section{Konukçu türünün soliter endoparazitoitin (Venturia canescens Grav.) bazı biyolojik özelliklerine etkileri}

\author{
Ali Boz, Adem Gülel, Nevran Eylem Akman Gündüz* \\ Ondokuz Mayıs Üniversitesi, Fen Edebiyat Fakültesi Biyoloji Bölümü, Samsun/Türkiye \\ *Sorumlu yazar/corresponding author: gunduzeylem@gmail.com
}

Geliş/Received 23/02/2018～Kabul/Accepted 04/10/2018
Anahtar Sözcükler: Venturia canescens Endoparazitoid Konukçu Gelişim süresi Ömür uzunluğu Verim

The effects of host species on some biological characteristics of solitary endoparasitoid (Venturia canescens Grav.)

\section{ABSTRACT}

In this study, the effects of three host species on development time, fecundity and adult longevity of parasitoid Venturia canescens Grav. (Hymenoptera: Ichneumonidae) were investigated. Cadra cautella (Walker) (Lepidoptera: Pyralidae), Plodia interpunctella (Hübner) (Lepidoptera: Pyralidae) and Ephestia kuehniella (Zeller) (Lepidoptera: Pyralidae) were used as hosts for V. canescens.

Host species had a significant effect on preadult development period of parasitoid. Development time was shortest on P. interpunctella, intermediate on C. cautella and longest on E. kuehniella. The fecundity of V. canescens was influenced by host species. It was higher on C. cautella and E. kuehniella larvae compared to P. interpunctella larvae. Feeding with honey increased the fecundity of parasitoid on all of the host species.

For longevity experiments, adult parasitoids were provided by either honey and host, honey and no host, no honey and host, or they were fed on neither honey nor host for their lifetimes. Host species did not significantly affect the longevity of unfed females with no oviposition opportunity and unfed females with oviposition opportunity. However, it significantly affected the longevity of fed females with no oviposition opportunity and fed females with oviposition opportunity. Females without host access lived longest when fed on honey and shorter in the other host access/feeding treatments.
Keywords:

Venturia canescens

Endoparasitoid

Host

Development time

Longevity

Fecundity 


\section{Giriş}

Parazitoit böcekler, ergin öncesi gelişimlerini diğer böcekler üzerinde tamamlayan ve ergin olduklarında serbest yaşayan canlılardır. Bu böcekler, ergin öncesi gelişimlerini tamamlayabilmek için gerekli olan protein, lipit ve karbonhidrat gibi önemli organik maddeleri konukçularının hemolenf ve/veya dokularında beslenerek karşılarlar (Quicke, 1997; Godfray, 1994). Parazitoitlerin belirli bir grubunu oluşturan koinobiont türlerde larvalar yumurtadan çıktıktan sonra sadece hemolenfle beslendikleri için, gelişimlerinin erken evrelerinde konukçunun doku ve organlarında önemli bir hasara neden olmazlar. Fakat larvalar ilerleyen gelişim evrelerinde konukçunun doku ve organlarını besin olarak tüketmeye başlarlar ve sonunda genellikle konukçunun tamamını tüketirler. İdiobiont parazitoitler hareketsiz konukçulara (yumurta-pupa) saldırdıkları veya parazitleme anında konukçularını felç ederek öldürdükleri için konukçunun besinsel kompozisyonu parazitoitin sonraki gelişimi için sabit hale gelmektedir. $\mathrm{Bu}$ yüzden idiobiont parazitoitlerde konukçu larvaların vücut büyüklüğü besin kalitesinin bir göstergesi olarak kabul edilmektedir (Godfray, 1994; Gündüz ve Gülel, 2005). Bu parazitoitlerde parazitoit büyüklügü konukçu büyüklüğü ile birlikte artma eğilimindedir. Konukçu büyüklügü ile ilişkili olarak parazitoit büyüklüğündeki bu artış parazitoitin verim ve ömür uzunluğu gibi diğer biyolojik özelliklerini de etkilemektedir (Godfray, 1994; Quicke, 1997). Koinobiont parazitoitlerde ise konukçular parazitlenme sonrası gelişimlerine devam edebilir ve parazitoitler konukçularının besinsel kaynaklarını kendi ihtiyaçlarına göre düzenleyebilirler. $\mathrm{Bu}$ nedenle koinobiontlarda, konukçu büyüklüğü ile parazitoit büyüklüğü ve gelişim süreleri arasındaki ilişkide ekofizyolojik faktörler oldukça önemlidir (Strand, 2002; Harvey ve Strand, 2003). Ergin parazitoitler ergin öncesi gelişim evrelerinden farklı olarak, konukçuya bağımlı olmadıkları ve serbest yaşadıkları için, doğada balözü, polen, nektar, reçine ve sakız gibi alternatif bazı besin kaynaklarına sahiptirler. Ayrıca dişi parazitoitler felçleştirmek ve/veya yumurta bırakmak için konukçularını deldiklerinde konukçunun hemolenfi ile de beslenebilirler (Jervis ve Kidd, 1986). Gerek ergin öncesi evrede gerekse ergin evrede alınan besinin kalite ve kantitesinin, parazitoitin gelişme süresi, verim, eşey oranı ve ömür uzunluğu gibi birçok biyolojik özelliğini etkilediği değişik araştırıcılar tarafindan tespit edilmiştir (Azzouz ve ark., 2004; Harvey ve ark., 2012).

Bir soliter endoparazitoit tür olan Venturia canescens ile ilgili çalışmalarda daha çok parazitoitin doğal çevredeki beslenme ve enerji dinamikleri (Casas ve ark., 2003), üreme başarısı ve yumurta üretimi (Eliopoulos ve ark., 2003; Roberts ve Schmidt, 2004; Gökçek, 2005), konukçu parazitoit ilişkileri (Harvey, 1996; Harvey ve Vet, 1997; Özkan, 1999; Rahman ve ark., 2007), gelişim süreleri (Harvey ve Strand, 2002; Özkan ve ark., 2003) ele alınmıştır. Biyolojik kontrolün başarısı, konukçu-parazitoit veya konukçu-ajan ilişkisi yanında, kullanılacak ajanın istenilen zamanda istenilen sayıda üretilebilmesine bağlıdır. Bu nedenle parazitoitin ergin öncesi gelişimini tamamlayabildiği değişik konukçular kullanılarak en iyi konukçunun seçilmesi önemli bir konu olmaktadır.

$\mathrm{Bu}$ çalışmada, farklı konukçu türlerinin $V$. canescens 'in ergin öncesi gelişim süresi, verim ve ergin hayat uzunluğuna etkisinin belirlenmesi amaçlanmıştır. $V$. canescens'in ergin öncesi gelişimini tamamlamak için kullandığı konukçu türleri ile parazitoitin biyolojik özellikleri arasındaki ilişkinin ortaya konulmasının, biyolojik mücadelede karşılaşılan konukçu uygunluğu ve konukçu düzenlemesi gibi bazı sorunların çözümüne katkı sağlayacağı düşünülmektedir.

\section{Materyal ve Yöntem}

\subsection{Materyal}

$\mathrm{Bu}$ çalışmada parazitoit olarak soliter, koinobiont, endoparazitoit Venturia canescens (Grav.) (Hymenoptera: Ichneumonidae), konukçu olarak Cadra cautella (Walker) (Lepidoptera: Pyralidae), Plodia interpunctella (Hübner) (Lepidoptera: Pyralidae) ve Ephestia kuehniella (Zeller) (Lepidoptera: Pyralidae)'nın larvaları kullanılmıştır. Çalışmalara parazitoit ve konukçuların stok kültürlerinin kurulmasıyla başlanmıştır.

\section{a. Yöntem}

\section{2. 1. Konukçu kültürlerinin kurulması}

Parazitoitin ergin öncesi gelişimini tamamlayabildiği türlerden konukçu olarak kullanılan $C$. cautella ve $P$. interpunctella erginleri, içerisinde ruşeym, gliserol ve kuru maya (10:2:1) içeren yapay besin bulunan ve ağzı hava sirkülasyonunu önlemeyecek şekilde bez ile kapatılmış bir litrelik cam kavanozlara konulmuştur. Kavanozlar $25 \pm 2{ }^{\circ} \mathrm{C}$ sıcaklık, \% $65 \pm 5$ bağıl nem ve sürekli aydınlık koşullara sahip laboratuvarda muhafaza edilmiştir. $\mathrm{Bu}$ işlem belirli zaman aralıklarında tekrarlanarak iki konukçu türüne ait stok kültürler oluşturulmuştur. Konukçu olarak kullanılan üçüncü tür E. kuehniella erginleri için besin olarak misır unu kullanılmıştır. Stok kültürlerin oluşturulması ve devam ettirilmesinde diğer iki konukçu için kullanılan ve yukarıda açılanan yöntem izlenmiştir. Bu kültürlerden elde edilen larvalar parazitoilerin yetiştirilmesinde konukçu olarak kullanılmıştır.

\section{2. 2. Parazitoit kültürlerinin kurulması}

Parazitoit $V$. canescens kültürleri, konukçuların yetiştirildiği laboratuvar şartlarında $12 \mathrm{~cm}$ çapındaki petri kaplarında hazırlanmıştır. Petri kaplarının tabanına konukçular için belirlenen besin maddesinden az miktarda konulup, bunun üzerine konukçu stok 
kültüründen alınan 30 adet konukçu larvası ve beş adet ergin dişi parazitoit konulmuştur. Stok kültürün devamını sağlanmak için gün aşırı yeni parazitoit kültürleri hazırlanmıştır.

\section{2. 3. Konukçu türünün parazitoitin gelişim süresi ve verimine etkisi}

Konukçu türünün parazitoit $V$. canescens'in gelişim süresi ve verimine etkisi ile ilgili denemeler $9 \mathrm{~cm}$ çaplı petri kapları kullanılarak daha önce belirtilen laboratuvar koşullarında yapılmıştır. Denemeler her konukçu türü için ayrı ayrı gerçekleştirilmiştir. Belirli bir konukçu ile yapılan çalışma sırasında, ergin öncesi geliş̧imini o konukçuda tamamlayan parazitoit stok kültüründen elde edilen 0-24 saat yaşındaki parazitoit dişileri kullanılmıştır. Her denemede 10 adet konukçu larvası alınıp içinde konukçuya ait besin bulunan petri kabına konulmuştur. Besin verilen gruplarda bu şekilde hazırlanan her petri kabına bir adet ergin parazitoit dişisi ve bunun beslenmesi için \% 50’lik bal çözeltisi emdirilmiş pamuk yerleştirilmiştir. Bir gün sonra parazitoit dişisi bu petri kabından alınıp, içerisinde aynı konukçuya ait 10 tane parazitlenmemiş larva, konukçu besini ve ballı pamuk bulunan bir başka petri kabına aktarılmıştır. Bu işleme parazitoit dişisi ölünceye kadar devam edilmiştir. Besin verilmeyen deneme grupları besin verilen gruplar gibi hazırlanmış ancak bu gruplardaki dişi parazitoitlere besin olarak kullanılan ballı pamuk verilmemiştir. Denemelerde kullanılan petri kaplarının üzerine tarih yazılarak, her gün parazitoit erginlerinin ne zaman çımaya başladıkları takip edilmiştir. Parazitoitlerin çıkış tarihleri kaydedilerek parazitoitlerin yumurtadan ergine kadar geçen gelişim süreleri ve her bir petri kabından çıan parazitoit sayıları günlük olarak kaydedilerek dişinin verimi belirlenmiştir. $\mathrm{Bu}$ şekilde denenen her konukçu türü için, populasyondan farklı zamanlarda alınan erginlerle beşer petrilik beş deneme grubu oluşturulmuştur.

\section{2. 4. Konukçu türünün ergin parazitoitin ömür uzunluğuna etkisi}

Konukçu türünün parazitoitin gelişim süresi ve verimine etkisini belirlemek için yapılan denemelerde kullanılan ve yukarıda detaylı olarak açıklanan denemelerdeki dişilerin öldükleri günler kaydedilerek sadece konukçu verilen ve konukçu ile birlikte bal verilen ömür uzunluğu deneme gruplarına ait veriler elde edilmiştir. Sadece bal verilen ve ne bal ne de konukçu verilmeyen deneme gruplarını oluşturmak için ise belirli bir konukçudan elde edilen parazitoit dişileri ergin oldukları gün tek tek olacak şekilde ayrılmıştır. Bir gruptaki parazitoitlere besin olarak ballı pamuk verilirken, diğer gruptakilere ne bal ne de konukçu verilmemiştir. Tüpler her gün kontrol edilerek parazitoitlerin öldükleri tarihler kaydedilmiş ve bu sonuçlar parazitoitin ömür uzunluğuna ait veriler olarak değerlendirilmiştir.

\section{2. 5. Elde edilen verilerin istatistiksel olarak değerlendirilmesi}

Elde edilen verilerin istatistiksel olarak değerlendirilmesinde ikiden fazla grubun karşılaştırılmasında tek yönlü varyans analizi (ANOVA) kullanılmıştır. $\mathrm{Bu}$ testten elde edilen sonuçların önem seviyeleri "Student-Newman-Kuel (SNK)" testi kullanılarak değerlendirilmiştir. Değerlendirilmelerde 0.05 güven sınırı $(\mathrm{P})$ esas alınmıştır. $\mathrm{P}>0.05$ ise ortalamalar arasındaki fark önemsiz, $\mathrm{P} \leq 0.05$ ise fark önemli olarak değerlendirilmiştir. İkili grupların karşılaştırılmasında ise "Bağımsız İki Örneklem t Testi" kullanılmış ve $\alpha=0.05$ güven sınırında değerlendirilmiştir.

\section{Bulgular ve Tartışma}

\subsection{Konukçu türünün parazitoitin gelişim süresi ve verimine etkisi}

Parazitoit $V$. canescens' in ergin öncesi gelişim süresi ve verimine konukçu türünün etkisi ile ilgili deneme sonuçları Çizelge 1'de verilmiştir.

Çizelge 1'den görüldüğü gibi parazitoitin gelişim süresi, ergin öncesi gelişimini tamamladığ 1 konukçu türüne bağlı olarak değişmiştir ve bu değişim istatistiksel açıdan önemli bulunmuştur ( $\mathrm{P} \leq 0.05)$. Konukçu olarak $C$. cautella kullanıldığında ergin öncesi gelişim süresi ortalama 24.85 gün, E. kuehniella kullanıldığında ortalama 25.02 gün ve $P$. interpunctella'da ortalama 24.03 gün olarak tespit edilmiştir.

Çizelge 1. Konukçu türünün parazitoit Venturia canescens'in gelişim süresi ve verimine etkisi

\begin{tabular}{cccc}
\hline \multirow{2}{*}{ Konukçu Türü } & $\begin{array}{c}\text { Parazitoitin Gelişim Süresi } \\
(\text { Gün }) \\
(\text { Ort } \pm \text { SH) }\end{array}$ & Beslenen & \multicolumn{2}{c}{$\begin{array}{c}\text { Verim (Birey sayıs1) Dişi-1 } \\
(\text { Ort } \pm \text { SH) }\end{array}$} \\
\cline { 3 - 4 } Cadra cautella & $24.85 \pm 0.03 \mathrm{~b}$ & $70.76 \pm 4.36 \mathrm{a}$ & Beslenmeyen \\
\hline Ephestia kuehniella & $25.02 \pm 0.02 \mathrm{a}$ & $74.84 \pm 4.48 \mathrm{a}$ & $9.44 \pm 0.62 \mathrm{a}^{*}$ \\
Plodia interpunctella & $24.03 \pm 0.05 \mathrm{c}$ & $28.28 \pm 2.11 \mathrm{~b}$ & $5.52 \pm 0.52 \mathrm{~b}^{*}$ \\
\hline
\end{tabular}


Konukçu büyüklüğünün ve bununla ilişkili olarak besin kalitesinin parazitoit türlerinin gelişim süresini etkilediği diğer birçok araştırıcı tarafindan da gösterilmiştir (Sequeira ve Mackauer, 1992a; Harvey ve Vet, 1997; Harvey ve Strand, 2003). Gündüz ve Gülel (2005) idiobiont parazitoit Bracon hebator'un ergin öncesi gelișim süresinin konukçu türüne bağlı olarak değiştiğini ve Galleria mellonella üzerinde gelişen parazitoitlerin ergin öncesi gelişim sürelerinin $E$. kuehniella üzerinde gelişenlere göre daha kısa olduğunu belirlemişlerdir. Rivers ve Denlinger (1995) üç farklı sarcophagid türü ile yaptıkları çalışmada Musca domestica'da yetiştirilen parazitoit Nasonia vitripennis'in gelişim süresinin daha uzun, vücut büyüklüğünün ve veriminin daha az olduğunu belirlemișlerdir. Farklı konukçu türleri içerdikleri kaynaklar bakımından kalitatif ve kantitatif olarak farkl1lık gösterdikleri için, parazitoitlerin büyüme ve gelişmesinin yetiştirildiği konukçu türüne bağlı olarak değişiklik göstermesi doğaldır.

Parazitoit ergin dişilerinde ovaryum gelişimi ve yumurta üretimi için besin maddeleri gerekir (Wheeler, 1996; Heimpel ve ark., 1997; Ueno, 1999; Kapranas ve Luck, 2008). Dişiler ihtiyaç duydukları besin maddelerinin bir kısmını, ergin öncesi gelișimleri sırasında konukçudan bir kısmını da ergin dönemde aldıkları besinlerden elde ederler. Pek çok böcek türünde karbonhidratlar, enerji ihtiyaçlarını karşılamak için veya çeşitli metabolit öncüleri olarak gerekmektedir. Ayrıca sinovigenik parazitoitlerde karbonhidratlar dişilerin yumurta üretimi için de gerekli olmaktadır. $\mathrm{Bu}$ nedenle parazitoitler özellikle ergin dönemde karbonhidrat eksikliğine duyarlı olurlar ve doğada sürekli olarak nektar, polen, bitki özsuyu gibi karbonhidrat bakımından zengin besin kaynaklarını ararlar.

$\mathrm{Bu}$ çalışmada, ergin parazitoit dişilerinden elde edilen verimin, ergin öncesi gelişimlerini tamamladıkları konukçu türüne ve besin (ballı pamuk) verilip verilmeme durumuna göre önemli derecede değiştiği belirlenmiştir $(\mathrm{P} \leq 0.05)$ (Çizelge 1). Besin verilen gruplarda dişi başına düşen birey sayısı $C$. cautella'da ortalama 70.76 birey, E. kuehniella'da 74.84 birey ve $P$. interpunctella'da 28.28 birey olarak tespit edilmiştir. Konukçu olarak $P$. interpunctella kullanıldığında elde edilen ortalama verim değeri diğer iki konukçudan elde edilen verim değerlerinden istatistiksel açıdan farklı bulunmuştur $(\mathrm{P} \leq 0.05)$. Buna karşıllk C. cautella ve E. kuehniella'dan elde edilen ortalama verim değerleri arasında önemli bir farkl1lık yoktur $(\mathrm{P}>0.05)$. Çizelge 1 incelendiğinde, besin verilmeyen gruplardan elde edilen verimin beslenenlere göre oldukça düşük olduğu görülmektedir. Besin verilmeyen gruplarda dişi başına düşen birey sayısı $C$. cautella'da ortalama 8.44 birey, E. kuehniella'da 9.64 birey ve $P$. interpunctella'da 5.52 birey olmuştur.

Konukçu türünün parazitoitlerin verimi üzerinde etkili olduğu diğer araştırıcıların çalışmalarında da gösterilmiştir. Smith ve Pimentel (1969) iki farklı konukçuda ergin öncesi gelişimini tamamlayan parazitoit $N$. vitripennis' 'in ömür uzunluğu ve veriminin konukçu türüne bağl1 olarak önemli ölçüde değiştiğini belirlemişlerdir. Arakawa ve ark. (2004) yumurtaları farklı büyüklükte olan üç konukçu türünde gelişen yumurta parazitoiti Trissolcus mitsukurii'nin ergin vücut büyüklüğü, ömür uzunluğu ve verimini karşılaştırmışlar ve konukçu büyüklüğü arttıkça ergin parazitoitin belirlenen özelliklerinde artış olduğunu göstermişlerdir. Sampaio ve ark. (2008) beş farklı konukçu türünde yetiştirilen afit parazitoiti Aphidius colemani'nin büyüklüğünün ve uyumunun yetiştirildiği konukçu türünün büyüklüğü ile yakından ilişkili olduğunu belirlemişlerdir. $\mathrm{Bu}$ araştırıcılar farklı konukçu türlerinde yetiştirilen ergin dişi parazitoitlerin yumurta yüklerinin yetiştirildikleri konukçu büyüklüğünden çok bu konukçularda gelişen parazitoit larvalarının besin maddelerini elde etme yetenekleri ile ilişkili olduğunu ileri sürmüşlerdir (Sampaio ve ark. 2008).

Beslenme parazitoitlerin verimi üzerinde etkili olan bir diğer faktördür. Schmale ve ark. (2001) konak Acanthoscelides obtectus larvalarında yetiştirilen üç farklı parazitoit türünde beslenmenin her üç parazitoit türünde de ömür uzunluğu ve verimi artırdığını belirlemişlerdir. Bezemer ve ark. (2005) sinovigenik ektoparazitoit Mastrus ridibundus'da ergin dönemde beslenmenin, vücut büyüklüğü ve üreme parametreleri üzerindeki etkilerini araştırdıkları çalışmada, besin verilmeyen parazitoitlerin düşük verime sahip olduklarını, daha az sayıda konukçuya saldırdıklarını ve yumurtalarının besin verilenlerin yumurtalarına göre daha küçük olduğunu belirlemişlerdir. Kapranas ve Luck (2008) sinovigenik olan iki farklı parazitoit türünde konukçu yokluğunun, konukçudan beslenmenin, beslenilen konukçunun büyüklüğünün, yumurta verimine ve ayrica besin tipinin parazitoitin ömür uzunluğuna etkilerini araştırmışlardır. $\mathrm{Bu}$ çalışmada, yalnızca karbonhidratla beslenenlerde parazitoit yumurtalarının neredeyse hiç yumurta kalmayıncaya kadar yavaş yavaş geri absorbe edildiği gösterilmiştir. Ayrıca dişilerin beslendiği konukçu büyüklüğünün ve besin miktarının olgun yumurta sayısını artırdığı, açlığın ise ergin ömür uzunluğunu büyük ölçüde sınırlandırdığı belirlenmiştir (Kapranas ve Luck, 2008).

\subsection{Konukçu türünün ergin parazitoitin ömür uzunluğuna etkisi}

Parazitoit $V$. canescens'in ergin öncesi gelişimini tamamladığı konukçu türünün ve ergin parazitoitlere besin ve/veya konukçu verilip verilmemesinin ergin parazitoitin ömür uzunluğuna etkisi ile ilgili deneme sonuçları Çizelge 2'de verilmiştir.

Çizelge 2'de görüldüğü gibi parazitoitin ergin öncesi gelişimini tamamladığı konukçu türü, erginlere besin verilip verilmemesi, besinle birlikte konukçunun 
bulunup bulunmaması veya sadece konukçu verilmesi $V$. canescens erginlerinin ömür uzunluğunu etkilemiştir. Parazitoit erginlerinden sadece konukçu verilenler ile besin ve konukçu verilmeyenlerin çok kısa yaşadıkları, bu iki gruptaki erginlerin ömür uzunluğu ortalamalarının istatistiksel olarak birbirinden farklı olmadığı görülmektedir $(\mathrm{P}>0.05)$ (Çizelge 2). Konukçu verilen parazitoit erginlerinde; ergin parazitoite $C$. cautella verildiğinde ortalama 2 gün, E. kuehniella verildiğinde ortalama 1.92 gün ve $P$. interpunctella verildiğinde ortalama 1.92 gün yaşadığı belirlenmiştir. Besin ve konukçu verilmeyen parazitoit erginlerinde belirlenen ömür uzunluğu sonuçları ergin öncesi gelişimlerini $C$. cautella'da tamamlayanlar için ortalama 2.94 gün, E. kuehniella' da tamamlayanlar için ortalama 3.12 gün ve $P$. interpunctella'da tamamlayanlar için ortalama 3.24 gün olarak belirlenmiștir.

$\mathrm{Bu}$ iki grubun aksine sadece besin verilen veya konukçu ve besin verilen $V$. canescens erginlerinin ömür uzunlukları konukçu türüne bağlı olarak değişmiştir (Çizelge 2). Sadece besin verilen fakat konukçu verilmeyen erginlerden, ergin öncesi gelişimlerini $C$. cautella'da tamamlayanların ortalama 47.48 gün, E. kuehniella'da tamamlayanların ortalama 48.70 gün ve $P$. interpuctella'da tamamlayanların ortalama 40.74 gün yaşadıkları tespit edilmiştir. $\mathrm{Bu}$ deneme grubundaki parazitoitlerin ömür uzunluğu verileri istatistiksel açıdan değerlendirildiğinde, $E$. kuehniella veya $C$. cautella türlerinden elde edilen parazitoitlerin ömür uzunluklarının birbirinden farklı olmadığı $(\mathrm{P}>0.05)$ ancak $P$. interpunctella'dan elde edilen parazitoitlerin diğer iki konukçudan elde edilenlere göre daha kısa süre yaşadıkları belirlenmiştir $(\mathrm{P} \leq 0.05)$.

Besin ile birlikte konukçu verilen gruplarda parazitoit erginlerinin ortalama ömür uzunluğunun konukçu türüne bağlı olarak değiştiği tespit edilmiştir ( $\mathrm{P}$ $\leq 0.05$ ) (Çizelge 2). Bu grupta C. cautella, E. kuehniella ve $P$. interpunctella'dan elde edilen erginlerin ortalama ömür uzunlukları sırasıyla 36.20 gün, 26.40 gün ve 10.64 gün olduğu ve bu değerlerin istatistiksel açıdan birbirinden farklı olduğu belirlenmiştir $(\mathrm{P} \leq 0.05)$.

Parazitoitlerde ergin öncesi gelişimin tamamlandığ 1 konukçu türünün ve erginlerin beslenip beslenmemelerinin ömür uzunluğunu etkilediği değişik araştırıcılar tarafindan tespit edilmiştir. Heimpel ve ark. (1997) Aphytis melinus ile yaptıkları çalışmada ergin evrede bal ve konukçu ile beslenmenin ergin yaşam süresini artırdığını belirlemişlerdir. Sood ve Pajni (2006) parazitoit Uscana mukerjii türünde bal ile beslenmenin ergin dişi parazitoitlerin ömür uzunluğunu ve verimini artırdığını göstermişlerdir. Işıtan ve ark. (2010) B. hebetor ile yaptıkları çalışmada, sadece besin veya besin + konukçu verilen erginlerin sadece konukçu verilenlere göre daha uzun yaşadıklarını belirlemişlerdir. Harvey ve ark. (2012) iki hiperparazitoit türü ile yaptıkları çalışmada bal ve farklı şekerlerle beslenmenin yalnızca suyla beslenenlere göre ömür uzunluğunu artırdığını göstermişlerdir.

Yapılan çalışmalar $V$. canescens'in konukçudan beslenemediğini ve pek çok parazitoitte de olduğu gibi diğer böceklerden farklı olarak karbonhidratlardan lipit sentezi yapamadığını göstermiştir (Casas ve ark., 2003; Visser ve Ellers, 2008). Sadece konukçu verilen erginlerin, besin ve konukçu verilmeyen erginler gibi kısa süre yaşamaları açık olarak $V$. canescens erginlerinin konukçu hemolenfinden yararlanmadıklarını göstermektedir. Bu bulgumuz besin kaynakları olarak değişik araştırıcılar tarafindan tüm parazitoit erginlerinde konukçudan beslenme olmadığını gösteren bulgulara paralellik göstermektedir (Jervis ve Kidd, 1986; Heimpel ve Collier, 1996). Besin ile birlikte konukçu verilen erginlerdeki ömür uzunluğunun sadece besin verilenlerden daha kısa olması, bu gruptaki dişilerin enerjilerinin bir kısmını bulundukları ortamdaki konukçuya yumurta bırakmak için harcamalarından kaynaklanmış olabilir. Üreme faaliyetinin ergin yaşama süresini etkilediği göz önüne alındığı zaman bu durumun şaşırtıcı olmadığı görülecektir. Ergin öncesi gelişim sırasında depolanan bazı maddeler ergin hayattaki bazı biyolojik aktiviteleri (Sequeira ve Mackauer, 1992b) etkilediğinden, ömür uzunluklarının parazitoitin yetiştirildiği konukçu türüne bağlı olarak değişmesi parazitoitin ergin öncesi gelişimi sırasında konukçulardan aldığı maddelerin kalitatif ve kantitatif olarak farklı olmasına bağlanabilir.

Çizelge 2. Konukçu türünün ve besin şartlarının parazitoit Venturia canescens'in ömür uzunluğuna etkisi

\begin{tabular}{cccc}
\hline \multirow{2}{*}{ Besin-konukçu durumu } & \multicolumn{3}{c}{ Ömür Uzunluğu (Gün) (Ort \pm SH) } \\
\cline { 2 - 4 } & Cadra cautella & Ephestia kuehniella & Plodia interpunctella \\
\cline { 2 - 4 } & $2.94 \pm 0.12 \mathrm{cA}$ & $3.12 \pm 0.09 \mathrm{cA}$ & $3.24 \pm 0.12 \mathrm{cA}$ \\
Besin + konukçu yok & $2.00 \pm 0.08 \mathrm{cA}$ & $1.92 \pm 0.09 \mathrm{cA}$ & $1.92 \pm 0.11 \mathrm{cA}$ \\
Sadece konukçu & $47.48 \pm 1.19 \mathrm{aA}$ & $48.70 \pm 1.23 \mathrm{aA}$ & $40.74 \pm 1.64 \mathrm{aB}$ \\
Sadece besin & $36.20 \pm 2.00 \mathrm{bA}$ & $26.40 \pm 1.61 \mathrm{bB}$ & $10.64 \pm 0.63 \mathrm{bC}$ \\
Besin + konukçu &
\end{tabular}

Aynı satırda aynı büyük harfi, aynı sütunda aynı küçük harfi taşıyan ortalamalar arasındaki fark önemsizdir $(\mathrm{P}>0.05)$

\section{Sonuç}

Biyolojik mücadele ajanı olarak kullanılacak parazitoitlerin etkinliklerinin artırılması ve kitle üretimlerinin etkili şekilde yapılması için konukçu uygunluklarının belirlenmesi gerekmektedir. Çünkü 
parazitoitlerin ergin öncesi gelişimlerini başarılı bir şekilde tamamlayabilmeleri konukçunun uygunluğuna ve kalitesine bağlıdır. Konukçu uygunluğunda, konukçunun büyüklüğü, yaşı, evresi, parazitoit birden çok konukçuda gelişimini tamamlayabiliyorsa konukçu türü, konukçunun daha önce parazitlenmiş olup olmaması, konukçunun parazitlenme sonrası besinsel yönden parazitoit larvalarının gelişimi için uygun hale getirilmesi gibi faktörler önemli rol oynar. Kaliteli konukçularda gelişen parazitoitlerin larval gelişimleri süresince depoladıkları temel besin maddeleri, onların ergin olduktan sonra ömür uzunluğu ve verim gibi bazı önemli hayatsal faaliyetlerini doğrudan etkiler.

$\mathrm{Bu}$ çalışmada soliter bir parazitoit türü olan $V$. canescens Lepidoptera takımına ait üç farklı konukçu türü kullanılarak yetiştirildiğinde, parazitoitin yumurtadan ergine kadar olan gelişim süresi, verim ve ergin ömür uzunluğu gibi özelliklerinin konukçu türünden etkilendiği belirlenmiştir. Ayrıca, parazitoitlerin ergin olduktan sonra beslenip beslenmemesinin de verim ve ömür uzunluğu üzerinde etkili olduğu gösterilmiştir. Çalışmadan elde edilen gelişim süresi, verim ve ömür uzunluğu ile ilgili sonuçlar birlikte değerlendirildiğinde, $C$. cautella türünün $V$. canescens için diğer konukçulara oranla daha uygun bir konukçu olduğu söylenebilir. Ancak çalışmadaki parazitoit-konukçu ilişkilerinin daha iyi değerlendirilebilmesi için farklı konukçu türlerinin ve bu konukçularda yetiştirilen parazitoitlerin biyokimyasal analizlerin yapılması ve her iki grupta da protein, lipit ve karbonhidrat gibi temel besin maddelerinin kalitatif ve kantitatif açıdan değerlendirilmesi gereklidir.

\section{Kaynaklar}

Arakawa, R., Miura, M., Fujita, M., 2004. Effects of host species on the body size, fecundity, and longevity of Trissolcus mitsukurii (Hymenoptera: Scelionidae), a solitary egg parasitoid of stink bugs. Applied Entomology and Zoology, 39 (1): 177-181. doi:10.1303/aez.2004.177.

Azzouz, H., Giordanengob, P., Wäckers, F.L., Laure K., 2004. Effects of feeding frequency and sugar concentration on behavior and longevity of the adult aphid parasitoid: Aphidius ervi (Haliday) (Hymenoptera: Braconidae). Biological Control, 31: 445-452. doi:10.1016/j.biocontrol.2004.07.013.

Bezemer, T.M., Harvey, J.A., Mills, N.J., 2005. Influence of adult nutrition on the relationship between body size and reproductive parameters in a parasitoid wasp, Ecological Entomology, 30: 571580. doi:10.1111/j.0307-6946.2005.00726.x.

Casas, J., Driessen, G., Mandon, N., Wielaard, S., Desouhant, E., van Alphen, J.J.M., Lapchin, L., Rivero, A., Christides, J.P., Bernstein, C., 2003. Energy dynamics in a parasitoid foraging in the wild. Journal of Animal Ecology, 72: 691-697. doi:10.1046/j.1365-2656.2003.00740.x.
Eliopoulos, P.A., Harvey J.A., Athanassiou, C.G., Stathas, G.J., 2003. Effect of biotic and abiotic factors on reproductive parameters of the synovigenic endoparasitoid Venturia canescens. Physiological Entomology, 28: 268-275. doi:10.1111/j.1365-3032.2003.00341.x.

Godfray, H.J.C., 1994. Parasitoids; Behavioral and Evolutionary Ecology, Princeton University Press, 488 p. Princeton, NJ.

Gökçek, N., 2005. Farklı besin ortamlarında yetiştirilen değişik konukçularda koinobiont parazitoit Venturia canescens (Hym.: Ichneumonidae)'nin gelişimi. Yüksek Lisans Tezi. Ankara Üniversitesi Fen Bilimleri Enstitüsü, 71s, Ankara.

Gündüz, N.E.A., Gülel A., 2005. Ergin yaş1 ve konukçu türünün parazitoit Bracon hebetor (Say) (Hymenoptera: Braconidae)'un gelişme süresine etkisi. Ondokuz Mayıs Üniversitesi Ziraat Fakültesi Dergisi, 20 (2): 31-36.

Harvey, J.A., 1996. Venturia canescens parasitizing Galleria melonella and Anagasta kuehniella: is the parasitoid a conformer or regulator? Journal of Insect Physiology, 42: 1017-1025. doi:10.1016/S0022-1910(96)00069-8.

Harvey, J.A. and Vet E.M., 1997. Venturia canescens parasitizing Galleria mellonella and Anagasta kuehniella differing suitability of two hosts with highly variable growth potential. Entomologia Experimentalis et Applicata, 84: 93-100. doi:10.1046/j.1570-7458.1997.00202.x.

Harvey, J. A., Strand, M.R., 2002. The developmental strategies of endoparasitoid wasps vary with host feeding ecology. Ecology, 83: 2439-2451. doi:10.1890/00129658(2002)083[2439:TDSOEW]2.0.CO;2.

Harvey, J.A., Strand, M.R., 2003. Sexual size and development time dimorphism in a parasitoid wasp: an exception to the rule. European of Journal of Entomology, $100 \quad$ (4): $\quad 485$ 492. doi: 10.14411/eje.2003.074.

Harvey, J.A., Cloutier, J., Visser, B., Ellers, J., Wackers, F.L., Gols, R., 2012. The effect of different dietary sugars and honey on longevity and fecundity in two hyperparasitoid wasps. Journal of Insect Physiology, 58 (6): 816-23. doi:10.1016/j.jinsphys.2012.03.002.

Heimpel, G., Collier, T.R., 1996. The evolution of hostfeeding behaviour in insect parasitoids. Biological Reviews, 71 (3): 373-400. doi:10.1111/j.1469185X.1996.tb01279.x.

Heimpel, G.E., Rosenheim, J.A., Kattari, D., 1997. Adult feeding and lifetime reproductive success in the parasitoid Aphytis melinus. Entomologia Experimentalis et Applicata, 83: 305-315. doi:10.1046/j.1570-7458.1997.00185.x.

Işıtan, Ö.V., Gülel A., Gündüz E.A., 2010. Farklı sicaklık ve besin tipinin parazitoit Bracon hebetor (Say, 1836) (Hymenoptera: Braconidae)'un ömür uzunluğuna etkisi. Türk Entomoloji Dergisi, 34 (3): 351-360. 
Jervis, M.A., Kidd N.A.C., 1986. Host-feeding strategies in Hymenopteran parasitoids. Biological Reviews, 61: 395-434. doi:10.1111/j.1469185X.1986.tb00660.x.

Kapranas, A., Luck, R.F., 2008. Egg maturation, host feeding, and longevity in two Metaphycus species parasitoids of soft scale insects. Biological Control, 47: 147-153. doi:10.1016/j.biocontrol.2008.08.002.

Quicke, D.L.J., 1997. Parasitic Wasps. Chapman \& Hall, Cambridge University Press, 470 p, London.

Özkan, C., 1999. Venturia canescens (Grav.) (Hymenoptera: Ichneumonidae) ile Ephestia kuehniella Zell. (Lepidoptera: Pyralidae) arasında bazı biyolojik ilişkiler üzerinde araştırmalar. Doktora Tezi. Ankara Üniversitesi Fen Bilimleri Enstitüsü, 97s, Ankara.

Özkan, C., Gökçek, N., Tunca, H., 2003. Development time, fecundity and longevity of Venturia canescens (Gravenhost) (Hymenoptera: Ichneumonidae) with Ephestia kuehniella Zeller (Lepidoptera: Pyralidae) as host. Integrated Protection of Stored Products. IOBC Bulletion/ wprs, Vol. 27, 173-175. 16-19 September, Kusadası.

Rahman, M.M., Roberts, H.L.S., Schmidt, O., 2007. Factors affecting growth in the koinobiont endoparasitoid Venturia canescens in the flour moth Ephestia kuehniella. Journal of Insect Physiology, 53: 463-467. doi:10.1016/j.jinsphys.2007.01.007.

Rivers, D.B., Denlinger, D.L., 1995. Fecundity and development of the ectoparasitic wasp Nasonia vitripennis are dependent on host quality. Entomologia Experimentalis et Applicata, 76 (1): 15-24. doi:10.1111/j.1570-7458.1995.tb01942.x.

Roberts, H.L.S., Schmidt, O., 2004. Lifetime egg maturation by host-deprived Venturia canescens. Journal of Insect Physiology, 50: 195-202. doi: 10.1016/j.jinsphys.2003.11.007.

Sampaio, M.V., Bueno, V.H.P., de Conti, B.F., 2008. The effect of the quality and size of host aphid species on the biological characteristics of Aphidius colemani (Hymenoptera: Braconidae: Aphidiinae). European Journal of Entomology, 105: 489494. doi: 10.14411/eje.2008.063.
Schmale, I., Wackers, F.L., Cardona, C., Dorn, S., 2001. Control potential of three Hymenopteran parasitoid species against the bean weevil in stored beans: the effect of adult parasitoid nutrition on longevity and progeny production. Biological Control, 21: 134139. doi:10.1006/bcon.2000.0911.

Sequeira, R., Mackauer, M., 1992a. Covariance of adult size and development time in the parasitoid wasp Aphidius ervi in relation to the size of its host, Acyrthosiphon pisum. Evolutionary Ecology, 6 (1): 34-44. doi:10.1007/BF02285332.

Sequeira, R., Mackauer, M., 1992b. Nutritional ecology of an insect host-parasitoid association: the pea aphid-Aphidius ervi system. Ecology, 73 (1): 183189. doi: 10.2307/1938730.

Smith, G.J.C., Pimentel D., 1969. The effect of two host species on the longevity and fertility of Nasonia vitripennis. Annuals of Entomological Society of America, 62: 305-308. doi: 10.1093/aesa/62.2.305.

Sood, S., Pajni, H.R., 2006. Effect of honey feeding on longevity and fecundity of Uscana mukerjii (Mani) (Hymenoptera: Trichogrammatidae), an egg parasitoid of bruchids attacking stored products (Coleoptera: Bruchidae). Journal of Stored Products Research, 42: 438-444. doi: $10.1016 /$ j.jspr.2004.08.001.

Strand, M.R., 2002. The interactions between larval stage parasitoids and their hosts. In Lewis E.E., Campbell J.F., Sukhdeo M.V.K. (Eds). The Behavioural Ecology of Parasites. CABI Publishing Cambridge. pp. 129-152.

Ueno, T., 1999. Reproduction and host-feeding in the solitary parasitoid wasp Pimpla nipponica (Hymenoptera: Ichneumonidae). Invertebrate Reproduction and Development. 35 (3): 231-237. doi: 10.1080/07924259.1999.9652389.

Visser, B., Ellers, J., 2008. Lack of lipogenesis in parasitoids: A review of physiological mechanisms and evolutionary implications. Journal of Insect Physiology, 54: 1315-1322. doi:10.1016/j.jinsphys.2008.07.014.

Wheeler, D., 1996. The role of nourishment in oogenesis. Annual Review of Entomology, 41: 407431. doi:10.1146/annurev.en.41.010196.002203. 